\title{
Non-neuronal acetylcholine: the missing link between sepsis, cancer, and delirium?
}

\author{
Adonis Sfera $^{1 *}$, Michael Cummings ${ }^{1}$ and Carolina Osorio ${ }^{2}$ \\ ${ }^{1}$ Psychiatry, Patton State Hospital, Patton, CA, USA, ${ }^{2}$ Psychiatry, Loma Linda University, Loma Linda, CA, USA
}

OPEN ACCESS

Edited by:

Ralf Landwehr,

Pfalzklinikum für Psychiatrie und

Neurologie, Germany

Reviewed by:

Francesco Panza,

University of Bari Aldo Moro, Italy

Mario Ulises Pérez-Zepeda,

Instituto Nacional

de Geriatría, Mexico

*Correspondence:

Adonis Sfera,

Psychiatry, Patton State Hospital, 3102 E Highland Ave, Patton,

CA 92369, USA

dr.sfera@gmail.com

Specialty section:

This article was submitted to Geriatric Medicine, a section of the

journal Frontiers in Medicine

Received: 24 June 2015

Accepted: 29 July 2015

Published: 21 August 2015

Citation:

Sfera A, Cummings $M$ and Osorio $C$ (2015) Non-neuronal acetylcholine:

the missing link between sepsis,

cancer, and delirium?

Front. Med. 2:56.

doi: 10.3389/fmed.2015.00056
The interaction between living organisms and the environment requires a balancing act between genomic and epigenomic forces. Inflammation and cellular proliferation are kept in check by the genes, which code for their components and the microRNAs, which are capable of silencing the transcription of these genes. Acetylcholine (ACh) may play a unique role in the maintenance of this equilibrium, as the epigenomic inhibition of the gene coding for nicotinic receptors, and disinhibits the gene causing anergia in immune cells. We hypothesize that age-induced ACh deficiency is the result of an epigenomic dysfunction of microRNA-6775 (miR-6775), which silences the transcription of CHRNA7 gene [coding for alpha 7 nicotinic cholinergic receptors (nAChRs)]. When silenced, this gene induces decreased expression of alpha $7 \mathrm{nAChRs,} \mathrm{which} \mathrm{may} \mathrm{predispose} \mathrm{elderly}$ individuals to inflammation, neuroinflammation, and delirium. We hypothesize further that miR-6775-induced hypocholinergia augments the expression of RNF 128, the gene related to anergy in lymphocytes (GRAIL). This gene favors regulatory $T$ cells (Tregs), promoters of immunologic tolerance, which may predispose to both cancer and sepsis-induced immunosuppression.

Keywords: acetylcholine, cell cycle, inflammation, carcinogenesis, immunosuppression

\section{Introduction}

Altered immunity, low-grade inflammation, and neuroinflammation accompany old age and may predispose to infections often progressing to sepsis, sepsis-induced delirium (SID), and cancer. Recent studies have shown that aging is associated with a body-wide decrease in nicotine binding to nicotinic acetylcholine receptors (nAChRs) $(1,2)$. Acetylcholine $(\mathrm{ACh})$ depletion is one of the bestdocumented hypotheses of delirium, and it is a common knowledge that old age and anticholinergic medications predispose to delirium. Recently, it was demonstrated that a preexisting impairment in cholinergic signaling was necessary for the pathogenesis of delirium (3).

Non-neuronal ACh is known to participate in cellular proliferation, differentiation, and apoptosis throughout the body tissues and organs; however, a direct link between ACh and immune cells' anergia has not been demonstrated. In this article, we hypothesize that age-related hypocholinergia predisposes not only to delirium but also to immunosenescence, which is often associated with increased risk for cancer and sepsis-induced immunosuppression (SAIS). 


\section{Method}

In order to test this hypothesis, we conducted a simple public domain search utilizing available on-line microRNA tools, including EXIQON miRSearch, DIANA-miRPath v3.0, and Wizemann Institute of Science miRBase, and identified miR-6775 (accession number MIMAT0027451) as being a regulator of both RNF 128 and CHRNA7 genes.

\section{Aging, Ach, and Low-Grade Inflammation}

The immune competent cells of the human body must be aggressive enough to "fire" promptly at intruding pathogens, but tolerant enough to avoid autoimmune "friendly fire." This delicate balance between too much and not enough inflammation is facilitated by a tight cooperation between the genom and the epigenom. Lack of epigenomic supervision, such as microRNA dysfunctions, may manifest as impairment in immunity or autoimmunity both of which are prevalent in elderly.

Recent studies demonstrate that aging is associated with lowered transcription of nAChRs with subsequent low-grade inflammation, as failure to properly activate alpha $7 \mathrm{nAChRs}$ results in release of pro-inflammatory cytokines (Figure 1). For example, postmortem studies of human brains with Alzheimer's disease (AD) reported up to $70 \%$ decrease in $n A C h R s$ expression (2). In addition, it was demonstrated that beta-amyloid itself can decrease transcription of nAChRs. With the same token, in sepsis, low expression of alpha $7 \mathrm{nAChRs}$ on peripheral blood mononuclear cells is associated with uncontrolled inflammation and poor prognosis, suggesting age-related predisposition for sepsis (4). Furthermore, recent studies show that nicotine protects against septic injury by activation of alpha $7 \mathrm{nAChRs}$, which probably inhibits tall-like receptors 4 (TLR4) (5).

Studies of prostaglandin pathways, such as cyclooxygenase (COX)-1 in microglia and perivascular macrophages, demonstrate that alteration in these pathways may predispose to cognitive dysfunction. Subsequently, COX-1 inhibitor SC-560 provides significant protection against LPS-induced cognitive deficits (8). These studies are consistent with the neuroinflammatory model of delirium. In addition, preclinical studies showed that COX-1 deficient $\left(\mathrm{COX}_{-1}^{-1-}\right)$ mice show not only reduced neuroinflammation and neuronal damage but also decreased cellular proliferation after lipopolysaccharide injection (9). Furthermore, during infection and inflammation, COXs enhance generation of prostaglandin E2 (PGE2). PGE2 is an immune-stimulator as it promotes T-cell activation and proliferation. Therefore, a dysfunction of miR-6775, silencing the expression of RNF 128 gene may result in excessive immune cells activation, including microglia via PGE2. This pathway may help explain the beneficial effect of COX-1 inhibitors in cognitive dysfunctions (10).

The RNF 128 gene codes for an enzyme, an ubiquitin ligase, which inhibits the transcription of IL- 2 and IL- 4 cytokine genes. Silencing these genes triggers proliferation of Tregs, the anergic $\mathrm{T}$ cell phenotype $(11,12)$. Tregs were shown to decrease mitogeninduced lymphocyte proliferation by directing these cells into apoptotic pathways, impairing immune responses $(13,14)$.

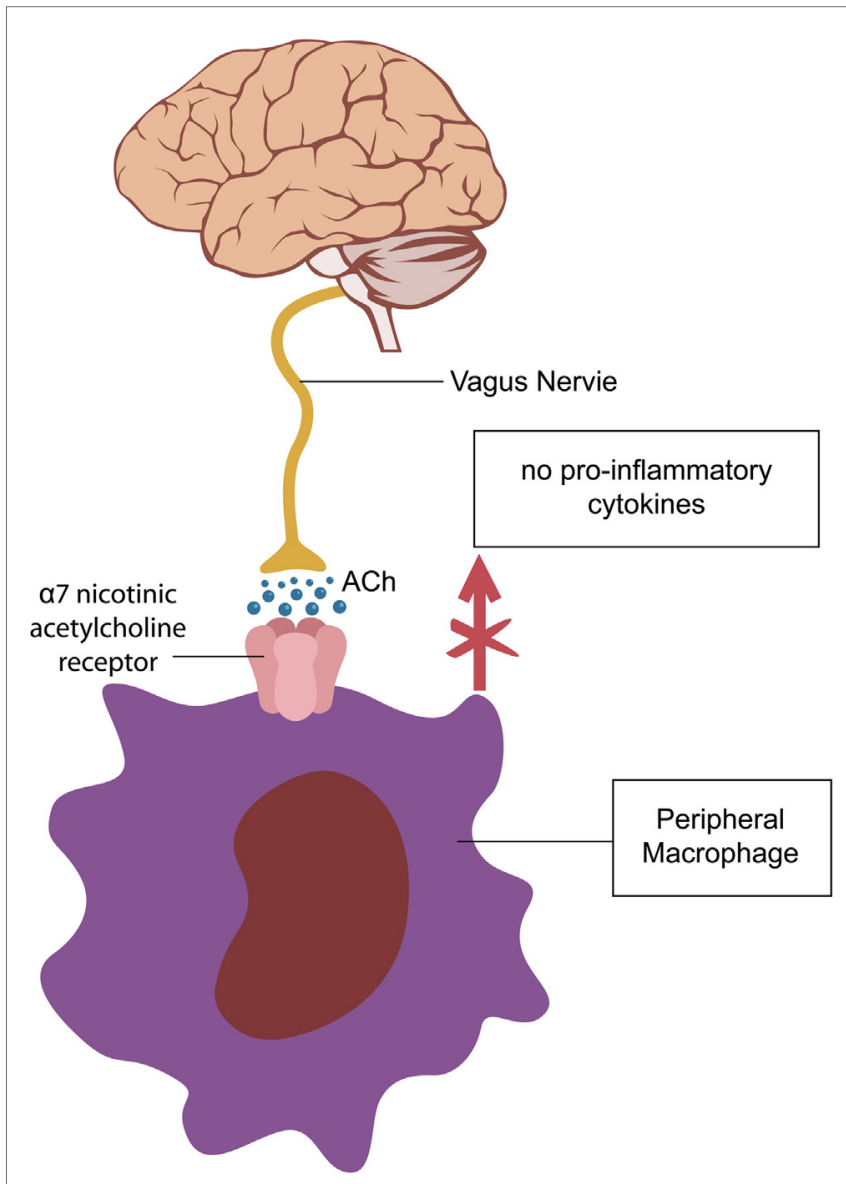

FIGURE 1 | Activation of alpha 7-cholinergic nicotinic receptors (nAChR) on peripheral macrophages decreases cytokine synthesis exerting an anti-inflammatory effect (5). A similar cholinergic pathway, regulating microglial activation is operational in the CNS $(6,7)$.

Furthermore, by promoting immune tolerance, Tregs are utilized in post-transplant management as they suppress allograft rejection (15). On the other hand, the absence of Tregs was demonstrated to trigger autoimmunity and inflammation by disinhibition of pro-inflammatory $\mathrm{T}$ helper cells 17 (Th17) (16). These cells access the CNS via diapedesis or through the recently described dural lymphatic vessels, spreading the inflammation into the brain (17). Interestingly, the proliferation of Th17 is augmented by the absence of alpha 7 nAChRs, suggesting that silencing CHRNA 7 gene, probably by microRNA, induces a Th17 response (16).

MicroRNAs (miRs) are a family of small non-coding RNAs, which are physiologically able to silence the expression of genes, which in return may activate or inhibit next tier genes. Therefore, a dysfunctional miR may decrease or increase transcription of genes depending on whether it silences the activator or the inhibitor of a particular gene. For example, aging was demonstrated to increase miR-23b, but decrease miR-17, miR-19b, miR-20a, and mir-106a, probably by silencing the activator genes $(18,19)$. Interestingly, miR$23 \mathrm{~b}$ was demonstrated to safeguard against autoimmunity and to regulate endothelial cells inflammation in sepsis $(20,21)$. 


\section{Non-Neuronal ACh and the Cell Cycle}

It has been known for more than a decade that peripheral lymphocytes derived from patients with $\mathrm{AD}$ proliferate less to mitogenic stimulation than lymphocytes derived from normal individuals, but a connection between the immune cells' proliferation, apoptosis, and ACh signaling has not been established $(22,23)$. ACh is well known for its neurotransmitter role at the synapses and the neuromuscular junctions, but its non-neuronal functions have only been documented lately (24). Non-neuronal ACh is released by different cells into the extracellular space (ECS) of numerous tissues, including the brain. Here, it operates in paracrine fashion, mainly by modulating cellular cytoskeleton, adapting it for proliferation, differentiation, or apoptosis, depending on the immediate cellular need (24). These non-neurotransmitter functions of ACh were documented both at phylogenetic and ontogenetic levels (25, 26). For example, phylogenetically, ACh was present in prokaryotic, eukaryotic cells, protozoa, fungi, and plants long before the evolution of a nervous system; ontogenetically, $\mathrm{ACh}$ has been detected in human embryos prior to neurogenesis or synaptogenesis (27).

The cholinergic system described on peripheral lymphocytes consists of choline acetyltransferase (ChAT), muscarinic and nicotinic ACh receptors (mAChRs and nAChRs), and acetylcholinesterase (AChE). Aside from inflammation, this system plays a major role in lymphocyte proliferation on antigen contact (26, 27). A non-neuronal cholinergic system was also described in the CNS comprised astrocytes, microglia, and endothelial cells (27). It was recently demonstrated that astrocytes secrete ChAT and that both neuronal and non-neuronal cells express nicotinic and muscarinic receptors, suggesting that inflammation and cellular proliferation may utilize paracrine ACh signaling (28). In the CNS, non-neuronal ACh is synthesized in the ECS from choline and acetyl coenzyme A in a reaction catalyzed by the astrocyte-secreted ChAT (28). Astrocytic pathology may impair ChAT biosynthesis, predisposing to inflammation and aberrant cellular proliferation (29). For example, deficient ACh signaling may induce post-mitotic neurons to enter the cell cycle, as demonstrated in AD. In this condition, neurons undergo apoptosis as they lack the cellular machinery to complete mitosis; they enter the cell cycle, progress through the $S$ phase, arrest in the G2 phase, and undergo pre-programed cell death (30-32).

Aside from affecting the neurons, aging was demonstrated to induce similar changes in astrocytes and microglia. For example, preclinical studies demonstrate that aging facilitates upregulation of astrocytic aquaporin-4 (AQP-4) proteins with resultant cytotoxic edema. Edematous astrocytes may be unable to synthesize ChAT, further impairing cholinergic signaling, and predisposing to delirium $(33,34)$. AQP-4 upregulation and astrocytic swelling were demonstrated in a variety of age-related diseases, including SID, stroke, traumatic brain injury (TBI), brain tumors or metastases, brain abscesses, and dehydration (34).

Astrocytic cytotoxic edema with decreased ACh signaling may be responsible for the aberrant neuronal re-entry into the cell cycle (34). Interestingly, another microRNA, miR-6739 (accession number MIMAT0027379), controls three genes: the cell division and apoptosis regulator 1 (CCAR1, ENSG 00000060339), regulator of cell cycle (RGCC, ENSG00000102760), and Meteorin glial cell differentiation regulator (METRN, ENSG 00000103260). These genes may link age-related changes in immunity with astrocyte pathology and neuronal re-entry into the cell cycle. Moreover, miR6775 and miR-6739 may regulate central and peripheral immunity (astrocytes are part of the innate immune system) and keep neuronal cell cycle in check, assuring stability of these cells in G0 phase.

Microglia are also components of the innate immune system, and impairments in cholinergic signaling were described in aging microglia. Interestingly, preclinical studies show that selective removal of senescent microglia from the brain of older animals can delay or prevent neurodegeneration (35). In addition, microglia-mediated neuroinflammation via TLR4 was hypothesized in the pathogenesis of post-operative delirium (36). Studies in rodents demonstrate that CHRNA 7 gene-induced expression of alpha $7 \mathrm{nAChRs}$ suppresses microglial inflammation and shifts these cells toward restorative phenotypes $(37,38)$. Therefore, miR-6775-induced silencing of CHRNA 7 gene favors microglial pro-inflammatory phenotype.

Other post-mitotic cells, such as cardiomyocytes, are known for their ability to re-enter the cell cycle and to synthesize ACh (39, 40). Recent studies demonstrate that ACh deficiency may induce apoptosis in cardiomyocytes, while vagal electrical stimulation in rodents was found to protect against it (41). In addition, the role of ACh in inducing cell cycle entry is relevant for carcinogenesis. For example, $\mathrm{mAChRs}$ activation in small cell lung carcinoma induces cancer cells to arrest in S and G2/M phases with a concomitant decrease in DNA synthesis (42). In human glioblastoma cells, ACh inhibits malignant cells' entry into the cell cycle via M2 receptor activation (43). Recently, it was demonstrated that cholinesterase enzymes decrease malignant cells proliferation in hepatocellular carcinoma (44). In other cancers, ACh seems to promote malignant growth, probably depending on the subtype of muscarinic receptors activated. For example, in colon cancer, upregulation of M3 muscarinic receptors is associated with increased malignant cells' proliferation (45).

Taken together these data suggest that ACh binding to $\mathrm{mAChRs}$, expressed by lymphocytes, triggers their proliferation in response to mitogens. Conversely, lack of such binding, caused by deficient $\mathrm{ACh}$, may result in immune anergia (12). On the other hand, in post-mitotic neurons, binding of ACh to mAChRs (or receptor subtypes) may keep the cell cycle in check by preventing exit from G0 phase. Deficient ACh binding may induce cell cycle instability with aberrant attempts to initiate mitosis (46).

\section{Conclusion}

The human immune system is hard-wired with the CNS by autonomic fibers and by the newly described dural lymphatic vessels. Low grade inflammation and neurosenescence were described in the elderly both in the immune system and the CNS, predisposing to aging pathology, such as infections, sepsis, and delirium. Dysfunctional miRs may be responsible for the age-related impairment in cholinergic signaling, inducing both inflammation and neuronal apoptosis after aberrant attempts to initiate the cell cycle. miR-6775 and miR-6739 may modulate inflammation, cell cycle, apoptosis, and glial functions, and may qualify for the name of "deliromiRs." 


\section{References}

1. Mitsis EM, Cosgrove KP, Staley JK, Bois F, Frohlich EB, Tamagnan $\mathrm{GD}$, et al. Age-related decline in nicotinic receptor availability with [123I]5-IA-85380 SPECT. Neurobiol Aging (2009) 30(9):1490-7. doi:10.1016/j. neurobiolaging.2007.12.008

2. Court J, Martin-Ruiz C, Piggott M, Spurden D, Griffiths M, Perry E. Nicotinic receptor abnormalities in Alzheimer's disease. Biol Psychiatry (2001) 49(3):175-84. doi:10.1016/S0006-3223(00)01116-1

3. Field RH, Gossen A, Cunningham C. Prior pathology in the basal forebrain cholinergic system predisposes to inflammation-induced working memory deficits: reconciling inflammatory and cholinergic hypotheses of delirium. $J$ Neurosci (2012) 32(18):6288-94. doi:10.1523/JNEUROSCI.4673-11.2012

4. Cedillo JL, Arnalich F, Martín-Sánchez C, Quesada A, Rios JJ, Maldifassi MC, et al. Usefulness of $\alpha 7$ nicotinic receptor messenger RNA levels in peripheral blood mononuclear cells as a marker for cholinergic antiinflammatory pathway activity in septic patients: results of a pilot study. J Infect Dis (2015) 211(1):146-55. doi:10.1093/infdis/jiu425

5. Kim TH, Kim SJ, Lee SM. Stimulation of the $\alpha 7$ nicotinic acetylcholine receptor protects against sepsis by inhibiting toll-like receptor via phosphoinositide 3-kinase activation. J Infect Dis (2014) 209(10):1668-77. doi:10.1093/infdis/ jit669

6. Huston JM, Ochani M, Rosas-Ballina M, Liao H, Ochani K, Pavlov VA, et al. Splenectomy inactivates the cholinergic antiinflammatory pathway during lethal endotoxemia and polymicrobial sepsis. J Exp Med (2006) 203:1623-8. doi:10.1084/jem.20052362

7. Shytle RD, Mori T, Townsend K, Vendrame M, Sun N, Zeng J, et al. Cholinergic modulation of microglial activation by alpha 7 nicotinic receptors. JNeurochem (2004) 89(2):337-43. doi:10.1046/j.1471-4159.2004.02347.x

8. Griffin ÉW, Skelly DT, Murray CL, Cunningham C. Cyclooxygenase-1dependent prostaglandins mediate susceptibility to systemic inflammation-induced acute cognitive dysfunction. J Neurosci (2013) 33(38):15248-58. doi:10.1523/JNEUROSCI.6361-11.2013

9. Russo I, Amornphimoltham P, Weigert R, Barlati S, Bosetti F. Cyclooxygenase-1 is involved in the inhibition of hippocampal neurogenesis after lipopolysaccharide-induced neuroinflammation. Cell Cycle (2011) 10(15):2568-73. doi:10.4161/cc.10.15.15946

10. Sreeramkumar V, Fresno M, Cuesta N. Prostaglandin E2 and T cells: friends or foes? Immunol Cell Biol (2012) 90:579-86. doi:10.1038/icb.2011.75

11. Vignali DAA, Collison LW, Workman CJ. How regulatory T cells work. Nat Rev Immunol (2008) 8(7):523-32. doi:10.1038/nri2343

12. Aziz M, Yang WY, Matsuo S, Sharma A, Zhou M, Wang P. Upregulation of GRAIL is associated with impaired CD4 T-cell proliferation in sepsis. J Immunol (2014) 192(5):2305-14. doi:10.4049/jimmunol.130216

13. Thornton AM, Shevach EM. Suppressor effector function of CD4+CD25+ immunoregulatory $\mathrm{T}$ cells is antigen nonspecific. JImmunol (2000) 164(1):183-90. doi:10.4049/jimmunol.164.1.183

14. Becker C, Bopp T, Jonuleit $\mathrm{H}$. Boosting regulatory $\mathrm{T}$ cell function by CD4 stimulation enters the clinic. Front Immunol (2012) 3:164. doi:10.3389/ fimmu.2012.00164

15. Hanidziar D, Koulmanda M. Inflammation and the balance of Treg and Th17 cells in transplant rejection and tolerance. Curr Opin Organ Transplant (2010) 15(4):411-5. doi:10.1097/MOT.0b013e32833b7929

16. Martinez GJ, Nurieva RI, Yang XO, Dong C. Regulation and function of proinflammatory TH17 cells. Ann N Y Acad Sci (2008) 1143:188-211. doi:10.1196/ annals.1443.021

17. Louveau A, Smirnov I, Keyes TJ, Eccles JD, Rouhani SJ, Peske JD, et al. Structural and functional features of central nervous system lymphatic vessels. Nature (2015) 523(7560):337-41. doi:10.1038/nature14432

18. Hackl M, Brunner S, Fortschegger K, Schreiner C, Micutkova L, Mück C, et al. miR-17, miR-19b, miR-20a, and miR-106a are down-regulated in human aging. Aging Cell (2010) 9(2):291-6. doi:10.1111/j.1474-9726.2010.00549.x

19. Dellago H, Preschitz-Kammerhofer B, Terlecki-Zaniewicz L, Schreiner C, Fortschegger K, Chang MW, et al. High levels of oncomiR-21 contribute to the senescence-induced growth arrest in normal human cells and its knock-down increases the replicative lifespan. Aging Cell (2013) 12(3):446-58. doi:10.1111/ acel.12069
20. Hu R, O'Connell RM. MiR-23b is a safeguard against autoimmunity. Nat Med (2012) 18(7):1009-10. doi:10.1038/nm.2849

21. Wu M, Jian-Teng G, Yi B, Zhong-Zhi T, Guo-Kai T. microRNA-23b regulates the expression of inflammatory factors in vascular endothelial cells during sepsis. Exp Ther Med (2015) 9(4):1125-32.

22. van Leeuwen LA, Hoozemans JJ. Physiological and pathophysiological functions of cell cycle proteins in post-mitotic neurons: implications for Alzheimer's disease. Acta Neuropathol (2015) 129(4):511-25. doi:10.1007/ s00401-015-1382-7

23. Currais A, Hortobágyi T, Soriano S. The neuronal cell cycle as a mechanism of pathogenesis in Alzheimer's disease. Aging (Albany NY) (2009) 1(4):363-71.

24. Wessler I, Kirkpatrick CJ. Acetylcholine beyond neurons: the non-neuronal cholinergic system in humans. Br J Pharmacol (2008) 154(8):1558-71. doi:10.1038/bjp.2008.185

25. Kawashima K, Fujii T. Basic and clinical aspects of non-neuronal acetylcholine: overview of non-neuronal cholinergic systems and their biological significance. J Pharmacol Sci (2008) 106(2):167-73. doi:10.1254/jphs.FM0070073

26. Kawashima K, Fujii T. Extraneuronal cholinergic system in lymphocytes. Pharmacol Ther (2000) 86:29-48. doi:10.1016/S0163-7258(99)00071-6

27. Kawashima K, Fujii T. Expression of non-neuronal acetylcholine in lymphocytes and its contribution to the regulation of immune function. Front Biosci (2004) 9:2063-85. doi:10.2741/1390

28. Vijayaraghavan S, Karami A, Aeinehband S, Behbahani H, Grandien A, Nilsson B, et al. Regulated extracellular choline acetyltransferase activity - the plausible missing link of the distant action of acetylcholine in the cholinergic anti-inflammatory pathway. PLoS One (2013) 8(6):e65936. doi:10.1371/ journal.pone.0065936

29. Sfera A, Osorio C, Price A, Gradini R, Cummings M. Delirium from the gliocentric perspective. Front Cell Neurosci (2015) 9:171. doi:10.3389/ fncel.2015.00171

30. Wojsiat J, Prandelli C, Laskowska-Kaszub K, Martín-Requero A, Wojda U. Oxidative stress and aberrant cell cycle in Alzheimer's disease lymphocytes: diagnostic prospects. J Alzheimers Dis (2015) 46:329-50. doi:10.3233/JAD-141977

31. Moh C, Kubiak JZ, Bajic VP, Zhu X, Smith MA, Lee HG. Cell cycle deregulation in the neurons of Alzheimer's disease. Results Probl Cell Differ (2011) 53:565-76. doi:10.1007/978-3-642-19065-0_23

32. Webber KM, Raina AK, Marlatt MW, Zhu X, Prat MI, Morelli L, et al. The cell cycle in Alzheimer disease: a unique target for neuropharmacology. Mech Ageing Dev (2005) 126(10):1019-25. doi:10.1016/j.mad.2005.03.024

33. Gupta RK, Kanungo M. Glial molecular alterations with mouse brain development and aging: up-regulation of the Kir4.1 and aquaporin-4. Age (Dordr) (2013) 35(1):59-67. doi:10.1007/s11357-011-9330-5

34. Thrane AS, Rangroo Thrane V, Nedergaard M. Drowning stars: reassessing the role of astrocytes in brain edema. Trends Neurosci (2014) 37(11):620-8. doi:10.1016/j.tins.2014.08.010

35. Michell-Robinson MA, Touil H, Healy LM, Owen DR, Durafourt BA, Bar-Or A, et al. Roles of microglia in brain development, tissue maintenance and repair. Brain (2015) 138(Pt 5):1138-59. doi:10.1093/brain/awv066

36. Jalleh R, Koh K, Choi B, Liu E, Maddison J, Hutchinson MR. Role of microglia and toll-like receptor 4 in the pathophysiology of delirium. Med Hypotheses (2012) 79(6):735-9. doi:10.1016/j.mehy.2012.08.013

37. Hua S, Ek CJ, Mallard C, Johansson ME. Perinatal hypoxia-ischemia reduces $\alpha$ 7 nicotinic receptor expression and selective $\alpha 7$ nicotinic receptor stimulation suppresses inflammation and promotes microglial Mox phenotype. Biomed Res Int (2014) 2014:718769. doi:10.1155/2014/718769

38. Suzuki T, Hide I, Matsubara A, Hama C, Harada K, Miyano K, et al. Microglial alpha7 nicotinic acetylcholine receptors drive a phospholipase C/IP3 pathway and modulate the cell activation toward a neuroprotective role. J Neurosci Res (2006) 83(8):1461-70. doi:10.1002/jnr.20850

39. Miao Y, Bi XY, Zhao M, Jiang HK, Liu JJ, Li DL, et al. Acetylcholine inhibits tumor necrosis factor $\alpha$ activated endoplasmic reticulum apoptotic pathway via EGFR-PI3K signaling in cardiomyocytes. J Cell Physiol (2015) 230(4):767-74. doi:10.1002/jcp. 24800

40. Roy A, Fields WC, Rocha-Resende C, Resende RR, Guatimosim S, Prado VF, et al. Cardiomyocyte-secreted acetylcholine is required for maintenance of homeostasis in the heart. FASEB J (2013) 27(12):5072-82. doi:10.1096/ f. $13-238279$ 
41. Kakinuma Y, Ando M, Kuwabara M, Katare RG, Okudela K, Kobayashi $\mathrm{M}$, et al. Acetylcholine from vagal stimulation protects cardiomyocytes against ischemia and hypoxia involving additive non-hypoxic induction of HIF-1alpha. FEBS Lett (2005) 579(10):2111-8. doi:10.1016/j.febslet.2005. 02.065

42. Williams CL, Lennon VA. Activation of muscarinic acetylcholine receptors inhibits cell cycle progression of small cell lung carcinoma. Cell Regul (1991) 2(5):373-81.

43. Ferretti M, Fabbiano C, Di Bari M, Conte C, Castigli E, Sciaccaluga M, et al. M2 receptor activation inhibits cell cycle progression and survival in human glioblastoma cells. J Cell Mol Med (2013) 17(4):552-66. doi:10.1111/ jcmm.12038

44. Pérez-Aguilar B, Vidal CJ, Palomec G, García-Dolores F, Gutiérrez-Ruiz MC, Bucio L, et al. Acetylcholinesterase is associated with a decrease in cell proliferation of hepatocellular carcinoma cells. Biochim Biophys Acta (2015) 1852(7):1380-7. doi:10.1016/j.bbadis.2015.04.003
45. Frucht H, Jensen RT, Dexter D, Yang WL, Xiao Y. Human colon cancer cell proliferation mediated by the M3 muscarinic cholinergic receptor. Clin Cancer Res (1999) 5(9):2532-9.

46. Herrup K, Yang Y. Cell cycle regulation in the postmitotic neuron:oxymoron or new biology. Nat Rev Neurosci (2007) 8:368-78. doi:10.1038/nrn2124

Conflict of Interest Statement: The authors declare that the research was conducted in the absence of any commercial or financial relationships that could be construed as a potential conflict of interest.

Copyright (c) 2015 Sfera, Cummings and Osorio. This is an open-access article distributed under the terms of the Creative Commons Attribution License (CC BY). The use, distribution or reproduction in other forums is permitted, provided the original author(s) or licensor are credited and that the original publication in this journal is cited, in accordance with accepted academic practice. No use, distribution or reproduction is permitted which does not comply with these terms. 